\title{
Экспедиционная деятельность П. Б. Балданжапова
}

\section{Марина Васильевна Аюшеева ${ }^{1}$}

\author{
${ }^{1}$ Институт монголоведения, буддологии и тибетологии СО РАН (д. 6, ул. Сахьяновой, \\ 670047 Улан-Удэ, Российская Федерация) \\ кандидат исторических наук, старший научный сотрудник \\ iD 0000-0003-3760-9867. E-mail: ayagma@yandex.ru
}

\author{
(c) КалмНЦ РАН, 2021 \\ (C) Аюшеева М. В., 2021
}

Аннотация. Введение. В статье рассмотрен один из аспектов творческого наследия Пурбо Балдановича Балданжапова (1921-1991), видного исследователя истории и культуры монголоязычных народов. Актуальность настоящей статьи продиктована значимостью материалов экспедиционной деятельности П. Б. Балданжапова, необходимостью ввода в научный оборот собранных им сведений по истории и культуре бурят, монголов и тувинцев. Цель и задачи исследования заключаются в оценке научного наследия П. Б. Балданжапова, ввода в научный оборот экспедиционных материалов и характеристики его роли в развитии бурятской науки. В исследовании применялись методы источниковедения для характеристики и анализа полевых материалов, биографический для оценки роли П. Б. Балданжапова в изучении истории и культуры монголоязычных народов. Материалом для изучения послужили его полевые материалы, отчеты, экспедиционные дневники и записные книжки, хранящиеся в личном архиве ученого (фонд № 29) в Центре восточных рукописей и ксилографов Института монголоведения, буддологии и тибетологии Сибирского отделения РАН. Результаты. В ходе своей многогранной научной деятельности П. Б. Балданжапов уделил много внимания сбору и выявлению письменных памятников, особенно монгольских летописных сочинений и сочинений по индо-тибетской медицине. Кроме этого, во время историко-этнографических экспедиций им проводился сбор сведений о шаманских обрядах, родовому составу, фольклору и этнографии. Собранные им материалы по духовной культуре бурят, монголов, по трансформации монгольского общества и развитию школьного образования в Монголии существенно дополняют и конкретизируют историю и культуру изучаемых народов. $B b l в o d b l$. П. Б. Балданжапов реализовал ряд крупных проектов по изучению письменных источников, духовной культуры бурят и монголов, индо-тибетской медицине. Экспедиционные материалы, большей частью представленные в черновых записях, трудны для расшифровки, но представляют определенную ценность для исследователей. Следует подчеркнуть, что собранная им коллекция архивных материалов, монгольских и тибетских рукописей и ксилографов, микрофильмов по тематическому насыщению является уникальной в собрании Центра восточных рукописей и ксилографов Института монголоведения, буддологии и тибетологии СО РАН.

Ключевые слова: письменные памятники, экспедиционные материалы, дневники, 
шаманизм, фольклор, Монголия, Бурятия, Центр восточных рукописей и ксилографов Института монголоведения, буддологии и тибетологии СО РАН

Благодарность. Статья выполнена в рамках государственного задания - проект «Письменные традиции народов Байкальского региона в контексте историко-культурного наследия России и Внутренней Азии» (номер госрегистрации: 121031000263-3). Для цитирования: Аюшеева М. В. Экспедиционная деятельность П. Б. Балданжапова // Монголоведение. 2021. Т. 13. № 4. С. 661-671. DOI: 10.22162/2500-1523-2021-4-661-671

\title{
Fieldwork Endeavors of Purbo B. Baldanzhapov
}

\section{Marina V. Ayusheeva ${ }^{1}$}

\author{
${ }^{1}$ Institute for Mongolian, Buddhist and Tibetan Studies, Siberian Branch of the RAS \\ (6, Sakhyanova St., 670047 Ulan-Ude, Russian Federation) \\ Cand. Sc. (History), Senior Research Associate \\ iD 0000-0003-3760-9867.E-mail: ayagma@yandex.ru
}

(C) KalmSC RAS, 2021

(C) Ayusheeva M. V., 2021

\begin{abstract}
The article examines one of the aspects of the creative heritage of Purbo Baldanovich Baldanzhapov (1921-1991), the eminent scholar of history and culture of Mongolian-speaking peoples. The study is of relevance, granted the importance of his field work and materials collected in the expeditions, including the data on the history and culture of Buryats, Mongolians, and Tuvans that need to be published. The article aims to give an estimate of Baldanzhapov's scholarly work and of his role for the development of science in Buryatia and to introduce his field materials to make them available for scientific study. For the purpose, methods of source studies were used for the description and analysis of the field materials under study and the biographical method was employed in the estimation of the scholar's contribution to the study of the history and culture of the Mongolian-speaking peoples. Materials used for the research were his field reports, reports, expedition diaries, and notebooks kept in the scholar's personal archive (f. no. 29) at the Center for Oriental Manuscripts and Xylographs of the Institute of Mongolian Studies, Buddhology and Tibetology, Siberian Branch of the Russian Academy of Sciences. Results. While he was involved in numerous scholarly activities, Baldanzhapov focused on the collection and identification of written monuments, especially Mongolian chronicles and works on Indo-Tibetan medicine. As a member of historical- ethnographic expeditions, he collected data on shamanistic rituals, Buryat clans and families, folklore, and ethnography. His data on the spiritual culture of the Buryats and Mongolians, the transformation of Mongolian society and the development of school education in Mongolia substantially supplement and concretize the history and culture of the peoples under study. Conclusions. Baldanzhapov managed to implement several large projects for the study of written sources, the spiritual culture of the Buryats and Mongolians, and Indo-Tibetan medicine. The draft records of most field materials are not easy to work with, but they are sure to be of relevance for the researchers in the field. Notably, in terms of their thematic coverage, the archival materials, Mongolian and Tibetan manuscripts and xylographs, microfilms, which the scholar managed to collect, are unique in the collection of the Center of Oriental Manuscripts and Xylographs of the Institute for Mongolian, Buddhist and Tibetan Studies (SB RAS).
\end{abstract}

Keywords: written sources, field materials, diaries, shamanism, folklore, Mongolia, Buryatia, Center of Oriental Manuscripts and Xylographs, Institute for Mongolian, Buddhist and Tibetan Studies of Siberian Branch of the RAS 


\section{Материалы IV Международного семинара «Письменное наследие \\ и актуальные проблемы истории и культуры монгольских народов», посвященного 100-летию со дня рождения Пурбо Балдановича Балданжапова}

Acknowledgements. The reported study was funded by government assignment, project no. 121031000263-3 'Writing Traditions of Baikal Peoples in the Context of Historical and Cultural Heritage of Russia and Inner Asia'.

For citation: Ayusheeva M. V. Fieldwork Endeavors of Purbo B. Baldanzhapov. Mongolian Studies (Elista). 2021; 13(4): 661-671. (In Russ.). DOI: 10.22162/2500-1523-2021-4-661-671

\section{Введение}

В Центре восточных рукописей и ксилографов Института монголоведения, буддологии и тибетологии СО РАН (ЦВРК ИМБТ СО РАН) особое место занимает личный архив Пурбо Балдановича Балданжапова (1921-1991), состоящий из нескольких коллекций: БМ - монгольские рукописи и ксилографы, БТ - тибетские рукописи и ксилографы, БА - личный архив ученого (в общей нумерации личных фондов — ЛАФ. № 29), ББ — востоковедная библиотека, Бм/ф - коллекция микрофильмов, а также фонозаписи, фотографии и газетные вырезки. Данное наследие было передано в дар Бурятскому институту общественных наук СО РАН (в настоящее время - ИМБТ СО РАН) вдовой Пурбо Балдановича Дулмой Дарижаповной Дарижаповой с условием хранения как неразрывного фонда. В 1995 г. в здании Хранилища восточных рукописей и ксилографов был организован мемориальный кабинет-музей П. Б. Балданжапова, в котором был частично восстановлен рабочий кабинет ученого: родные передали мебельные шкафы, рабочий стол, пишущую машинку со старописьменным монгольским шрифтом и другие личные вещи.

Следует подчеркнуть, что собранная им коллекция архивных материалов, монгольских и тибетских рукописей и ксилографов, микрофильмов по тематическому насыщению является уникальной в собрании ЦВРК ИМБТ СО РАН. И она привлекала внимание исследователей: обзор тибетского фонда был выполнен в работе Ю. Ж. Жабон [Жабон 2014], фонозаписи и фольклорные материалы исследовались в работах Л. Д. Дашиевой [Дашиева 2014], Д. В. Дашибаловой [Дашибалова 2014]. Д. В. Дашибаловой был выполнен перевод на русский язык улигера, записанного П. Б. Балданжаповым [Дашибалова 2014: 76-102]. Общая характеристика личного фонда содержится в статье С. В. Бураевой и М. В. Аюшеевой [Бураева, Аюшеева 2011]. Изучению неопубликованной рукописи П. Балданжапова «Тува под гнетом маньчжурских захватчиков» посвящены две статьи В. А. Василенко [Василенко 2012; Василенко 2013]. Большая часть материалов, собранных фондообразователем во время командировок и экспедиций, отложилась в рукописном виде и практически не была введена в научный оборот.

\section{Творческая биография}

П. Б. Балданжапов работал в Институте общественных наук с 1959 г., занимал должности младшего научного сотрудника, старшего научного сотрудника, заведующего музеем Восточных культур, заведующего сектором источниковедения индо-тибетской медицины. За эти годы им разрабатывались, главным образом, следующие крупные темы: «Источниковедение и историография МНР», «Источниковедение индо-тибетской медицины», «Изучение Ганджура и Данджура, выборочная публикация и перевод сочинений из них» [Гомбоева 2009: 77]. Все темы, так или иначе, переплетаются в его экспедиционных записях, 


\section{Монголоведение • Mongolian Studies • 2021 • T. 13 • № 4}

поскольку направлены на изучение богатого духовного и письменного наследия монгольских народов. В ходе своей многогранной научной деятельности П. Б. Балданжапов уделил много внимания сбору и выявлению письменных памятников, особенно монгольских летописных, грамматических сочинений и сочинений по индо-тибетской медицине, что соответствовало выполняемым им темам госзаданий. Проблема «Истории культуры» поднятая в рамках задач Госкомитета Совета Министров СССР по науке и технике, отразилась в статьях, посвященных изучению развития современной культуры монгольского народа.

\section{Экспедиционные исследования}

Сбор полевых материалов и начало научно-исследовательской работы относятся к раннему этапу его трудовой деятельности. Еще до поступления в Иркутский государственный университет Пурбо Балданович занимался сбором фольклорного и этнографического материала в Агинском округе.

В личном фонде отложилась переписка с А. П. Окладниковым за 1950 г. по организации археологической экспедиции на территории Агинского Бурятского округа. В последующем интерес к древней истории родного края был продолжен. В личном фонде имеется неопубликованная рукопись «Материалы по археологии Агинского национального округа» [ЦВРК ИМБТ СО РАН. ЛАФ. 29. Оп. 1. Д. 213]. Сохранился примерный план научно-исследовательской и агитационно-массовой экспедиции, составленный им 12 мая 1958 г. План состоял из трех крупных блоков: А) собирать материал по истории (данный пункт расписан более подробно и включал четыре подпункта: 1) запись фольклора - песни, сказки, загадки, легенды и предания; 2) материалы о колхозах, сомонах, районах и округе (какие роды проживали раньше, административное устройство, знаменательные события, известные личности, родство по отцу и матери); 3) обряды и обычаи прошлого (свадебные, сурхарбан, спортивные, суеверия); 4) топонимика; Б) запись на магнитофон (песен, сказок, легенд, соло, «хони абхуулха - тээглэхэ» и др.). Последний блок «В» заключал в себе и фотографирование. Помимо этого, был разработан особый план с маршрутом экспедиции. Во время данной экспедиции от улигершина Галсан-Жамсо Тыхеева были записаны на магнитофонную ленту улигеры «Алтан Шаахай Мунгэн Шаахай хоёр» («Алтан Шахай и Мунгэн Шахай»), «Уншэн сагаан ботогон» («Сиротинка белый верблюжонок») и др.

Во время историко-этнологической экспедиции отдела зарубежного Востока в Тункинский район Бурятии в мае - июне 1962 г. П. Б. Балданжаповым были собраны многочисленные фольклорные материалы. Записано краткое содержание ряда улигеров, тункинской версии Гэсэра. На магнитофон записаны улигеры «Угытэй хубуун» («Парень бедняк»), «Хаан Харангуй» («Хан Харангуй»), тексты мориной соло ('восхваление коня') и др. После сбора полевого материала при содействии райкома партии была организована научно-практическая конференция, в которой участвовали члены парткома, секретари парторганизаций, лекторы и другие активисты. Проводилась выставка «Наука и религия» с показом фотоматериала по священным местам Тунки. Были зачитаны антирелигиозные и пропагандистские доклады. П. Б. Балданжапов сделал доклад «Советское законодательство о культах». При райкоме партии также была организована беседа с ламами и шаманами, на которой Пурбо Балданович повторил свой 


\section{Материалы IV Международного семинара «Письменное наследие \\ и актуальные проблемы истории и культуры монгольских народов», посвященного 100-летию со дня рождения Пурбо Балдановича Балданжапова}

доклад и побеседовал с участниками в неформальной обстановке. Несмотря на то, что данная беседа была организована при райисполкоме «для разоблачения реакционной и незаконной деятельности служителей культа» [ЦВРК ИМБТ СО РАН. ОАФ 2007/г. Л. 22], П. Б. Балданжапов интересовался современным бытованием религиозных обрядов, их исполнением, содержанием и значением. Предполагалось, что в беседе будут принимать участие 6 лам и 17 шаманов, однако присутствовало 8 шаманов и 2 лам. После того как П. Б. Балданжапов прочитал им лекцию об их вредной деятельности и законах, принятых в советском государстве о культах, состоялась беседа, во время которой задавались такие вопросы, как: «Есть ли закон, запрещающий религию?», «Правильно ли забивать последнюю корову, чтобы съездить в Иволгинский дацан?», «Какие есть меры для прекращения того, чтобы население не молилось шаманам?». Из беседы явствует, что слушатели согласны с вредным влиянием религии, но все же продолжают проводить определенные ритуалы, как сэржэм и другие, по просьбе сельчан. О влиянии шаманских представлений и шаманов на сознание и культуру тункинских бурят свидетельствует история, рассказанная П. Б. Балданжапову прокурором Тункинского района, о том, что несколько лет назад в Галбае построили новую коровью ферму, но так как шаманы сказали, что та местность плохая, то ферму перенесли на другое место, на что было истрачено 100 тыс. рублей (старыми) [ЦВРК ИМБТ СО РАН. ОАФ 2007. Л. 56-61].

Среди полевых материалов Тункинской экспедиции много разрозненных записей о Шаргай-нойоне, или Ринчин-хане в ламаизированном культе, топонимике района, обоо, проводимых обрядах, охотничьих обрядах, о хонгодорах. Как следует из материалов, при достаточно высоком распространении религиозности молодежь не знает смысла и значения обрядов, а на религиозные мероприятия, как обоо, ходят как на традиционные, национальные мероприятия. Проводимые обряды по описанию стали просты. Некоторые информанты не помнят призываний, имен, атрибутов. Пурбо Балданович после приведенной информации делает пометки — «рассказано путано, сбивчиво».

Интересные легенды о происхождении хозяев гор были записаны от Хархоева Чойдона Цыденовича, 55 лет. Так, Дэмбээ-лхарамба из Закаменского Санагинского дацана рассказывал, что Шаргай-нойон и Буха-нойон были шаманами в далекой стране, возле Индии. От данного информанта был записан обряд тахилга Шаргай-нойона. При почитании хозяев местными жителями соблюдались определенные запреты: на поклонение не привозили сырое мясо, женщины не поднимались на возвышенность, возле святых мест не рубили деревья.

П. Б. Балданжаповым был записан текст охотничьих обрядов. Например, когда идут охотиться в незнакомую местность, читают: Хилгани эзэн хамба ламахай / Мэдээ угы мэлтэрхэйб / Ухаа угы ултархайб / Хуртэгтыл! / Хаани албан хатуу / Алба хуули заяагты! / Хаани албан хатуу / Хаһаг мангад бэрхэ / Хоол эдеэ заяагты! 'Хозяин Хилганы — хамбо ламахай / Случайно (подношение) перелил через край, / Неожиданно переварил, / Отведайте! / Ханская служба трудная / Пожалуйте нам строгий закон! / Ханская служба трудная / Казаки и русские умелые / Пожалуйте пропитание!'. В ламаизированном тексте поклонения остались старые формулы, присутствуют упоминания о тяжкой

1 Здесь и далее перевод автора. 


\section{Монголоведение • Mongolian Studies • 2021 • T. 13 • № 4}

службе царю и о умелых казаках. Считалось, что если не делать подношений в лесу, то возможны различные напасти, можно заплутать в лесу, встретиться с опасностью и пр.

Хомхоев Чойжон сообщил, при каких случаях раньше обращались к шаманам: при падеже скота, при болезни детей, плохих снах, для обретения покровительства хозяев-духов местностей. Последний обряд по истечении определенного времени повторялся, и снова обращались с просьбой о заботе и попечении, а при достижении опекаемым/молящимся определенного возраста во время обряда проговаривалось о том, что далее не надо оберегать, поскольку уже достиг нужных лет [ЦВРК ИМБТ СО РАН. ОАФ 2007. Л. 11].

Экспедиционный материал представлен рукописными и машинописными записями на бурятском языке. Имеются сведения о топонимике, даны объяснения названий местностей: Мон уула - гора Мон, названа так по имени шамана. Собирались данные о культовых местах, помимо широко известных обоо и мест поклонений Буха-нойону и Шаргай-нойону, были записаны названия местных обоо, часть из которых сейчас уже не посещается, забыта или уничтожена. Так, например, в прежнее время в Торах в местности Зуһалан было обоо, называемое Обоошо добуун, которое ныне распахано [ЦВРК ИМБТ СО РАН. ОАФ 2007. Л. 14]. При описании культовых мест перечислены предметы, имеющиеся там, - изображения буддийских божеств, ленточки, бумханы, цаца и прочее.

В материалах экспедиции негативно описаны места возле целебных источников, которые подвергаются стихийному паломничеству. Так, на одном из источников ванны были организованы в бочках из-под горючего, в которых подогревалась вода, кругом было грязно и сыро. В Харьбяатуе от информатора Мэлзэнова было записано, что в Туве, дальше за Окой, есть Жуйганский аршан, на который раньше ездили лечиться много тункинских бурят и где есть специальное место поклонения.

Во время Баргузинской экспедиции проходил семинар агитаторов, на котором присутствовало 22 человека. Здесь П. Б. Балданжапов также читал свой доклад «Советское законодательство о культах», на семинаре были рассмотрены задачи организации атеистической пропаганды. Баргузинско-курумканские материалы содержат отрывочные сведения по истории хамниганов и бурят, легенды о культовых местах и их описание, сведения об аршанах — целебных источниках. Также в беседах с информантами затрагивались вопросы родо-племенного состава, например, зафиксировано, что хамниганские рода частично отошли от бурятских родов: сангасир - от сонголов, галжагир - от галзутов.

В 1963 г. состоялась двухнедельная историко-этнографическая экспедиция в Селенгинский аймак Монголии по приглашению Селенгинского аймачного комитета Монгольской народно-революционной партии в рамках месячника монголо-советской дружбы, в рамках которой изучалась «проблема преодоления религиозных пережитков у монгольских аратов в сравнительном плане», а также современное состояние культуры и быт аратов [ЦВРК ИМБТ СО РАН. ОАФ 2007/г. Л. 2]. В состав экспедиции входили следующие научные сотрудники: Б. Д. Цибиков, К. М. Герасимова, П. Б. Балданжапов, П. И. Хадалов, Г. И. Заятуев, Л. П. Ямпилов и Р. Е. Пубаев. Экспедиция проходила по следующему маршруту: город Сухэбатор - госхоз Цагаан Толгой - сель- 


\section{Материалы IV Международного семинара «Письменное наследие \\ и актуальные проблемы истории и культуры монгольских народов», посвященного 100-летию со дня рождения Пурбо Балдановича Балданжапова}

хозобъединение Баруун Бурэн - госхоз Орхон - монастырь Амарбаясгалант хийд - Сухэбатор - город Зун-Хараа - сельхозобъединение Цэцэрлик - госхоз Зуун Бурэн - Сухэбатор.

Во время экспедиции проходили встречи с представителями администраций: секретарями аймачного комитета МНРП (особую поддержку оказал первый секретарь Селенгинского айкома МНРП тов. Банзарагч и секретарь айкома Шагдарсурэн), с директорами госхозов, учителями.

В орхонском госхозе были записаны исторические сведения, собраны сведения о выведенной орхонской породе овец, отличающейся высокими характеристиками по шерсти и весу, практически в два раза по сравнению с обычной овцой. В госхозе было 3 отделения, 30 тысяч овец, поголовье коров - 2500 , лошадей 1 000. При госхозе имелись подсобные хозяйства - пилорама, кирпичный и известковый заводы, также имелись 2 клуба, электростанция, врачебный пункт, детсад, ясли, восьмилетняя школа.

Пурбо Балданович собирал материал для своей работы по системе образования МНР. В госхозе Цагаан-толгой он посетил Цаган-толгойскую школу. Им были записаны сведения по истории школы, которая была открыта в 1928 г. при одном учителе, а во время экспедиции работало уже 4 учителя, в школе обучалось 87 учеников. Также была обследована Барун-бурэнская семилетняя школа. По записям П. Б. Балданжапова, эта школа была основана в 1925 г. в двух войлочных юртах при 15 учениках. Далее приведено расписание дня учеников.

Участники экспедиции осмотрели одиннадцатилетнюю школу в г. Зун-Хараа, основанную в 1960 г. При этой школе было организовано профориентированное образование: с 8 класса ученики изучали машиноведение и домоводство, с 9-го готовились механизаторы сельского хозяйства.

Членами экспедиции было отмечено, что в связи с коллективизацией и обоседлением аратского населения стало развиваться земледелие. Вероятно, в связи с этим П. Б. Балданжапов в своем отчете подробно остановился на рассмотрении работы пришкольного опытного участка, где имеется зимняя теплица и высажены овощи, злаки, плодовые деревья — яблони, ягодные кустарники: смородина, малина, также высажены осина, кедр, лиственница и пр. Под руководством учителя Гомбожава школьники учились агротехнике. Ежегодно план высадки овощных и злаковых культур менялся и утверждался дирекцией школы. Для работы на пришкольном участке ученики подразделялись на бригады с определенным графиком и расписанием, при этом функционировала просветительская бригада, которая выпускала настенную газету о достижениях пришкольного участка. Для получения хорошего и большого урожая применялись удобрения, которые готовил учитель Гомбожав. Пурбо Балданович также описал процесс подготовки семян и прочие тонкости ведения пришкольного участка [ЦВРК ИМБТ СО РАН. ОАФ. № 1997а. Л. 1-36].

П. Б. Балданжаповым разрабатывалась тема «Народное образование в МНР» (входила в тему по разработке проблемы «Закономерности развития социализма и перехода к коммунизму») и готовилась монографическая работа по данной проблематике. Им были подготовлены две главы «Зарождение и развитие народного образования в МНР (1921-1947 гг.)» и «Система народного образования в МНР». В данных главах автор дал историческую справку о развитии народного 


\section{Монголоведение • Mongolian Studies • 2021 • T. 13 • № 4}

образования, обобщил опыт передовых учителей, описал экономическую и культурную отсталость дореволюционной Монголии и роль МНРП в построении системы народного образования. Предполагалась, что работа «Народное образование в МНР» будет объемом в 15 авторских листов. В данной работе планировалась провести теоретическое осмысление закономерностей развития народного образования в условиях народно-демократического строя. Подчеркивалось, что данная книга будет иметь и практическое значение для других «освободившихся стран, как наглядный пример организации дела народного просвещения в условиях отсталости страны» [ЦВРК ИМБТ СО РАН. ЛАФ. 29. Оп. 1. Д. 36. Л. 35].

Среди материалов экспедиций в Монгольскую Народную Республику широко представлены сведения о системе школьного образования, фотографии школ, учеников в классах, а также достижений культуры (исполнители национальных танцев, актеры, певцы, музыканты) и трудовые будни работников-аратов. Во время данной экспедиции также были записаны интересные устные легенды и предания. В его дневниковых записях перемежаются разные сведения о численности учеников и расписания уроков с данными о религиозности населения, наименования редких книг, находящихся в аймачных библиотеках.

Разрабатывая тему историографии Монголии, П. Б. Балданжапов старался охватить как можно большую источниковую базу для исследования, помимо широко известных летописей и хроник, он разыскал редкие списки исторических сочинений. За годы работы им были охвачены не только крупные книгохранилища и востоковедные коллекции в России и Монголии, но и много аймачных библиотек, частных собраний. В конце 1967 - начале 1968 гг. состоялась поездка в Монголию, в ходе которой были проработаны аймачные библиотеки. В Орхонской аймачной библиотеке им были сняты копии с редких рукописей по истории буддизма в Тибете, Монголии и распространении его в Ордосе.

По возможности П. Б. Балданжаповым осуществлялся заказ на копирование, приобретение, снятие списка или микрофильмирование письменных памятников. В 60-е гг. прошлого столетия социалистическая культура довлела в массовом общественном сознании и старые формы культурной памяти утрачивали свою ценность и нужность. Нередко возникал риск утраты старинных рукописей, буддийских атрибутов. Деятельность П. Б. Балданжапова была направлена на сохранение культурного наследия монголов и бурят, в своих поездках он не только собирал по крупицам информацию о редких памятниках письменности и сами документы, предметы музейного значения, но и предпринимал меры к обеспечению их дальнейшего надлежащего хранения и бережного отношения.

В 1965 г. состоялась историко-этнографическая экспедиция по Читинской области в составе П. Б. Балданжапова и Б. Д. Бадараева. В обосновании данной поездки указывались оторванность и изолированность бурятского населения изучаемого ареала, недостаток отражения родоплеменного состава и этнического происхождения в современной исторической литературе, планировалось собрать сведения о религиозных пережитках в быту, также имелась информация о наличии значительного количества литературы, представляющей научный интерес. За время экспедиции были отработаны три населенных пункта - Бурсомон, Тадхалта Верхнешергольджинского сельсовета и Долонкор (Семиозерное) Харгацинского сельского совета. 


\section{Материалы IV Международного семинара «Письменное наследие \\ и актуальные проблемы истории и культуры монгольских народов», посвященного 100-летию со дня рождения Пурбо Балдановича Балданжапова}

Участниками экспедиции отмечалась скудность материалов по религиозному состоянию, в дальнейших поездках предполагалось также обратить основное внимание на современный быт и родоплеменной состав. Тем не менее, как выяснили участники экспедиции, в религиозном отношении шергольджинские буряты являлись буддистами-ламаитами без явно выраженных остатков шаманизма. Хотя в прежнее время они поклонялись следующим обоо: 1) Даша-дондок Обоо-хан, 2) Улдзытэ-ундэр Обоо-хан, 3) Бата-сагаан Обоо-хонгор, Баян-Хонгор уула, Аршаанта Улзы Хутагые оршогуулагша уула. На этих обоо поклонения проводили ламы, и с их исчезновением прекратилась практика поклонения. Легенды и предания об этих обоо не были обнаружены.

Были записаны легенды о переселении шергольджинских бурят. Во время поездки в Бурсомон членами экспедиции была осмотрена тибетоязычная коллекция, которую местные жители хранили в специально построенном помещении-дугане. Согласно сведениям, полученным от сторожа дугана старика Бадмаева Санжи, данные тексты были привезены из Тибета доромбо Балган Тугдэном. Это был местный лама, получивший образование в Тибете в монастыре Брайбун и привезший нартанский Ганджур, Юм и другую литературу. Экспедиция проработала в Бурсомоне 5 дней. Был проведен разбор имеющейся литературы, даны оценка и рекомендации по хранению.

Как руководитель Музея восточных культур Института общественных наук БФ СО АН СССР П. Б. Балданжапов организовал несколько научных экспедиций и командировок по сбору и атрибуции лекарственного сырья, сбору буддийской литературы, а также изучению буддийского наследия в комплексе. В июле 1968 г. экспедиция Музея восточных культур присутствовала на церемонии круговращения Майдари и сняла ее на киноленту. Отчет о проделанной работе содержит подробное описание данного хурала, порядок действий и их значение [ЦВРК ИМБТ СО РАН. ЛАФ. 29. Оп. 1. Д. 33. Л. 1-10].

В августе 1968 г. состоялась экспедиция в Танну-Туву. Собирались сведения о письменной и книжной культуре, лекарственных растениях. Трижды по черновым материалам встречаются записи о спрятанных в горах книгах, как, например, «книги Эрзинского дацана были вывезены на гору в районе колхоза Мурун» [ЦВРК ИМБТ СО РАН. ЛАФ. 29. Оп. 1. Д. 26. Л. 1], и многое другое.

\section{Выводы}

П. Б. Балданжапов за годы своей деятельности работал над несколькими крупными проектами, которые безусловно отнимали колоссальные трудо-временные ресурсы. Чем можно объяснить и малоразработанность его экспедиционных записей: кратких, емких, информативных. Следует подчеркнуть, что собранные им материалы фактически остались не введенными в научный оборот.

Экспедиционные материалы, большей частью представленные в черновых записях, трудны для расшифровки, но представляют определенную ценность для исследователей. Возросшая в обществе потребность к осмыслению своих исторических корней, традиционной культуре, возрождению многих обрядовых действий требует тщательного и взвешенного научного подхода к изучению рекультивации многих процессов, имеющих место в общественно-культурной и религиозной жизни бурятского общества. Ввиду 
вышеизложенного архивные материалы из фонда П. Б. Балданжапова могут способствовать выяснению значения, исторического бытования некоторых обрядов и культовых практик.

\section{Источники}

ЦВРК ИМБТ СО РАН - Центр восточных рукописей и ксилографов Института монголоведения, буддологии и тибетологии Сибирского отделения РАН.

\section{Sources}

Center of Oriental Manuscripts and Xylographs; Institute for Mongolian, Buddhist and Tibetan Studies (SB RAS).

\section{Литература}

Бураева, Аюшеева 2011 - Бураева С. В., Аюшеева М. В. Коллекции мемориального кабинета П. Б. Балданжапова // Культурное наследие и глобализация. Опыт, проблемы, перспективы сохранения культурных ценностей в современном мире: мат-лы междунар. науч.-практ. конф. (г. Сыктывкар, 21-23 сент. 2011 г.). Сыктывкар: Коми пединститут, 2011. С. 25-27.

Василенко 2012 - Василенко В. А. Неопубликованная рукопись Пурбо Балданжапова «Тува под гнетом маньчжурских захватчиков» // Новые исследования Тувы. 2012. № 2. С. $86-108$.

Василенко 2013 - Василенко В. А. Оценка П. Б. Балданжаповым политики Цинского Китая в Туве в период с XVII по XIX вв. (по материалам рукописи «Тува под гнетом маньчжурских захватчиков») // Исторические, философские, политические и юридические науки, культурология и искусствоведение. Вопросы теории и практики. 2013. № 4-2 (30). С. 34-38.

Дашибалова 2014 - Дашибалова Д. В. Улигер «Уншэн сагаан ботогон» в записи П. Б. Балданжапова // Культура Центральной Азии: письменные источники. 2014. № 8. С. $76-102$.

Дашиева 2014 - Дашиева Л. Д. Материалы П. Б. Балданжапова как источник изучения песенной традиции хори-бурят // Культура Центральной Азии: письменные источники. Культура Центральной Азии: письменные источники. 2014. № 8. С. 65-76.

Гомбоева 2009 - Гомбоева М. И. П. Б. Балданжапов (1921-1991) // Ученые записки Забайкальского государственного университета. Филология, история, востоковедение. 2009. С. 77-81.

Жабон 2014 — Жабон Ю. Ж. О тибетской коллекции П. Б. Балданжапова (1921-1991) (из фондов ЦВРК ИМБТ СО РАН) // Культура Центральной Азии: письменные источники. Культура Центральной Азии: письменные источники. 2014. № 8. С. 29-34.

\section{References}

Buraeva S. V., Ayusheeva M. V. Collections of the Baldanzhapov Memorial Room. In: Cultural Heritage and Globalization. Experiences, Problems, Prospects of Maintaining Cultural Values in the Contemporary World. Conference proceedings (Syktyvkar, September 2123, 2011). Syktyvkar: Komi State Pedagogical Institute, 2011. Pp. 25-27. (In Russ.)

Dashibalova D. V. Unshen Sagaan Botogon: The version recorded by Purbo Baldanzhapov. In: Culture of Central Asia. Written Sources. Collected papers. 2014. No. 8. Pp. 76-102. (In Russ.)

Dashieva L. D. Exploring the Khori Buryat song tradition: Materials collected by P. Baldanzhapov. In: Culture of Central Asia. Written Sources. Collected papers. 2014. No. 8. Pp. 65-76. (In Russ.)

Gomboeva M. I. Purbo B. Baldanzhapov, 1921-1991. Uchenye zapiski ZabGU. Filologiya, istoriya, vostokovedenie. 2009. Pp. 77-81. (In Russ.) 
Материалы IV Международного семинара «Письменное наследие

и актуальные проблемы истории и культуры монгольских народов», посвященного 100-летию со дня рождения Пурбо Балдановича Балданжапова

Vasilenko V. A. P. B. Baldanzhapov's assessment of Qing China policy in Tuva from the XVII th till the XIX ${ }^{\text {th }}$ centuries (by material of the manuscript 'Tuva under the Yoke of the Manchu Invaders'). Historical, Philosophical, Political and Law Sciences, Culturology and Study of Art. Issues of Theory and Practice. 2013. No. 4-2 (30). Pp. 34-38. (In Russ.)

Vasilenko V. A. Purbo Baldanzhapov's unpublished manuscript 'Tuva under the Yoke of the Manchu Invaders'. The New Research of Tuva. 2012. No. 2. Pp. 86-108. (In Russ.)

Zhabon Yu. Zh. Center of Oriental Manuscripts and Xylographs (IMBTS SB RAS): The Tibetan collection of P. Baldanzhapov (1921-1991) revisited. In: Culture of Central Asia. Written Sources. Collected papers. 2014. No. 8. Pp. 29-34. (In Russ.) 